\title{
A EDUCAÇÃO INTEGRAL NO BRASIL: DAS EXPERIÊNCIAS HISTÓRICAS AO PROGRAMA MAIS EDUCAÇÃO
}

\author{
LA EDUCACIÓN INTEGRAL EN BRASIL: DE LAS EXPERIENCIAS \\ HISTÓRICAS AL PROGRAMA MÁS EDUCACIÓN
}

\author{
COMPREHENSIVE EDUCATION IN BRAZIL: \\ FROM HISTORICAL EXPERIENCES TO THE PROGRAM \\ CALLED PROGRAMA MAIS EDUCAÇÃO
}

Camila Altmayer Valentini ${ }^{\mathrm{I}}$
Dinora Tereza Zucchetti

Resumo Recorte da pesquisa qualitativa intitulada "O currículo escolar e o Programa Mais Educação: um diálogo possível?", o artigo é um estudo de revisão teórica cujo objetivo é apresentar a trajetória histórica, social e política que consubstancia experiências de Educação Integral no Brasil. Desde Anísio Teixeira com o Centro Carneiro Ribeiro, passando por Darcy Ribeiro e os CIEPs, chega-se ao Programa Mais Educação, proposta contemporânea de ampliação da jornada escolar que sugere a indução à Educação Integral nas escolas públicas de Ensino Fundamental. O texto alude a experiências educativas que aproximam a assistência social ao campo da educação por meio de práticas socioeducativas, pautadas pela ideia de que crianças e adolescentes das classes populares demandam pela ampliação da jornada escolar. Mais tempo de escola, enquanto ação afirmativa, em uma sociedade de oportunidades desiguais, por vezes aproxima, em outras distâncias as experiências históricas em questão.

Palavras-chave: Educação; Educação Integral; Jornada Escolar Integral; Programa Mais EducaÇão.

Universidade Feevale (FEEVALE), Novo Hamburgo/RS - Brasil

II Universidade Feevale (FEEVALE), Novo Hamburgo/RS - Brasil 
Abstract Extract taken from the qualitative research entitled "The school curriculum and the program called Programa Mais Educação": a possible dialogue?, the article is a theoretical review study whose goal is to present the historical, social and political route which consubstantiates Comprehensive Education experiences in Brazil. From Anísio Teixeira with Centro Carneiro Ribeiro center, going through Darcy Ribeiro and the CIEPs, we get to the Programa Mais Educação program, a contemporary proposal to extend school hours which suggests the induction to Comprehensive Education in public Elementary Schools. The text alludes to educational experiences which bring social assistance closer to the educational area by means of socio-educational practices, ruled by the idea that children and teenagers belonging to the working classes demand by extending school hours. More hours at school, while an affirmative action in a society with unequal opportunities, sometimes brings closer and some other times drifts apart the aforementioned historical experiences. Key-words: Education; Comprehensive Education; Full School Day; Programa Mais EDUCAÇ̃̃o PROGRAM.

Resumen Recorte de la investigación cualitativa titulada "El currículo escolar y el Programa Más Educación: ¿un diálogo posible?", el artículo es un estudio de revisión teórica cuyo objetivo es presentar la trayectoria histórica, social y política que resume las experiencias de Educación Integral en Brasil. Desde Anísio Teixeira con el Centro Carneiro Ribeiro, pasando por Darcy Ribeiro y los CIEP, se llega al Programa Más Educación, una propuesta contemporánea de la ampliación de la jornada escolar que sugiere la inducción a la educación integral en las escuelas públicas de la Enseñanza Básica. El texto se refiere a las experiencias educativas que aproximan la asistencia social al campo de la educación a través de prácticas socioeducativas, basado en la idea de que los niños y los adolescentes de las clases populares demandan por la ampliación de la jornada escolar. Más tiempo de escuela, como una acción afirmativa, en una sociedad de oportunidades desiguales, algunas veces acerca, en otras aleja las experiencias históricas en cuestión.

Palabras clave: Educación; Educación Integral; Jornada Escolar Integral; Programa Más EduCACión.

\section{INTRODUÇÃo}

No sistema escolar brasileiro os objetivos e as intencionalidades em ofertar ensino público alternam-se frente a diferentes contextos sociais e políticos. O acesso gratuito e universal às instituições escolares é o resultado de um percurso marcado por lutas que passam pela garantia do direito à educação e reformulações nos sistemas de ensino. Disto resulta que a educação brasileira desenvolveu-se, de forma lenta, em distintos períodos, tendo em vista que a organização das estruturas de ensino transcorria (e transcorre) a partir de interesses predominantes. O mesmo se deu com as propostas de Educação Integral que, em diferentes momentos, entre avanços e retrocessos, expressam intencionalidades e interesses diversos. 
Para exemplificar o exposto, foi preciso realizar uma investigação de caráter histórico com início em 1930, década que foi palco de uma acentuada luta pela educação pública no Brasil. Nesse período, um grupo formado por intelectuais e educadores, denominados de Pioneiros da Escola Nova, objetivavam a renovação do ensino a partir da configuração política e social da época. Com a intenção de transformar a educação acessível a todos e com qualidade, destaca-se entre os escolanovistas o educador Anísio Teixeira que inaugurou, em 1951, na Bahia, a primeira experiência pública de Educação Integral no Brasil, o Centro Carneiro Ribeiro.

Seguindo os pressupostos de Teixeira, em 1980, Darcy Ribeiro, também renomado educador, cria outra proposta de escolas de Educação Integral, no Rio de Janeiro, os Centros Integrados de Educação Pública - CIEPs. Seu objetivo foi o de ofertar propostas e espaços físicos qualificados de formação que contemplassem diferentes interesses, oportunizando aos alunos, dessa forma, uma educação para a vida.

A partir dessas duas experiências, nos anos 2000, a Educação Integral retorna ao cenário educacional brasileiro por meio da proposta do Programa Mais Educação (PME). Criado, em 2007, pelo Ministério da Educação e Cultura, o PME é executado numa perspectiva de gestão intersetorial envolvendo um conjunto de Ministérios de áreas distintas. Numa parceria da União com os Estados e os municípios, objetiva induzir a Educação Integral na rede pública de ensino em todo o território brasileiro, por meio da ampliação da jornada escolar. Esse é o contexto que inspira o presente artigo de revisão teórica que procedeu a um denso estudo da literatura, realizada no enquadramento da problemática de uma pesquisa qualitativa de Dissertação de Mestrado, buscando por localizar as influências de Teixeira e de Ribeiro na implementação do Programa que pretende induzir a Educação Integral no Brasil de hoje.

\section{De Anísio TeiXeira a DARCy Ribeiro: a defesa da esCola PÚbliCa brasileira}

Anísio Teixeira e Darcy Ribeiro, dois exponenciais educadores e intelectuais brasileiros, foram fortemente atuantes nas causas pela educação no país. Lutaram pelo ideário de que somente o ensino público de qualidade poderia oportunizar as transformações sociais necessárias num Brasil extremamente desigual, em especial, do ponto de vista socioeconômico. Para ambos, a garantia do direito à educação transcendia o espaço e o currículo escolar. O ensino deveria estar próximo à realidade dos alunos, bem como, organizado com vistas à formação de sujeitos capazes de exercer a sua cidadania; questão emergente e de ensejo nacional, especialmente a partir de 1930.

Com o fim da Primeira República, ocorreu uma aceleração nas mudanças sociais e políticas, resultando num sutil avanço dos direitos sociais no país. Iniciaram-se ensaios sobre a participação política dos cidadãos brasileiros, os movimentos sociais ampliaram-se e organizaram-se para reivindicar direitos e, entre os resultados alcançados, posteriormente, nos anos de 1940, a criação do Ministério do Trabalho, Indústria e Comércio, o reconhecimento do trabalho feminino diurno, a consolidação dos sindicatos como personalidade jurídica pública, entre outros (CARVALHO, 2003). 
À luz desses avanços políticos, as relações de trabalho modificaram-se e passaram a ser reconhecidas legalmente. Os trabalhadores tiveram acesso a direitos estabelecidos por lei, como, a liberdade sindical, a igualdade salarial, o salário mínimo nacional, o repouso de férias e finais de semana, a delimitação da jornada de trabalho para oito horas diárias. Questões relativas à sociedade salarial que se fizeram frequentes diante dos processos de ampliação econômica do país, o que Lechner (1992) denominou como sendo "desenvolvimento pra dentro". Nesse contexto, o Estado promoveu a substituição de importações, alargou o mercado interno e ampliou os serviços públicos para as classes médias e pobres.

Por sua vez, no que tange à educação, ainda na década de 1930, foram publicados censos estatísticos que demonstravam a necessidade de repensar e reformular a educação no país; também porque, no processo de desenvolvimento econômico estabelecido, a educação não poderia ocupar o espaço de espectadora. Nessa perspectiva, Gadelha (2009, p. 186) afirma que:

\begin{abstract}
O Brasil precisava educar-se e modernizar-se sob os signos do progresso e da ciência e, para isso, precisava também articular-se internamente, costurando suas partes em uma unidade orgânica e planejando seu futuro como nação, que passava necessariamente pela industrialização. É por essa via que deve haver debates sobre o papel fundamental a ser cumprido pela educação e pela cultura, sobre a reforma do sistema educacional.
\end{abstract}

Nesse sentido, acompanhando o desenvolvimento emergente no Brasil e visando à reorganização e reestruturação do sistema escolar brasileiro, em 1932, 26 educadores assinaram o Manifesto dos Pioneiros da Educação Nova. Esse documento instituiu-se num marco no movimento de reconstrução educacional, apontando a educação como direito de todos e basilar para uma sociedade igualitária e ética. Defendia que a educação pública, obrigatória e laica, deveria ser responsabilidade do Estado e que sua oferta fosse voltada para todos, sem distinção de classes sociais ${ }^{1}$ (ARANHA, 2006).

O Manifesto contemplou diferentes aspectos não desenvolvidos no sistema escolar até o período em questão, pois buscava uma maior aproximação da escola com a base social existente. Pautava a qualificação do ensino por meio da oferta e gratuidade de acesso, a valorização do magistério e, principalmente, o estreitamento da relação entre escola e sociedade no que tange à formação dos sujeitos para o exercício da cidadania.

Entre os educadores que propunham a Escola Nova, destacam-se Anísio Teixeira, Cecília Meireles, Fernando de Azevedo, Edgard Roquette-Pinto. Eles objetivavam superar o distanciamento formativo que o sistema escolar aprofundava entre as pessoas, uma vez que o ensino acadêmico era voltado para a elite da sociedade e o profissional para os pobres.

Embora as reivindicações do Manifesto dos Pioneiros não tenham sido acolhidas na Constituição de 1934, houve uma ascendência do movimento pela participação dos educadores na Revista Brasileira de Estudos Pedagógicos (1944), publicada pelo Instituto Nacional de Estudos Pedagógicos (INEP - criado em 1938) e na elaboração da Lei de Diretrizes e Bases da Educação Nacional, projeto encaminhado ao Congresso Nacional, em 1948, com votação em 1961 (FONSECA, 2011). 
Conforme Anísio Teixeira, a formação do cidadão e da sociedade democrática dependia da reconstrução do sistema escolar brasileiro, as instituições deveriam abordar valores de convivência e cooperação, aspectos fundantes de uma verdadeira democracia. Assim, a escola enquanto ferramenta de formação expandiria as possibilidades dos sujeitos no âmbito pessoal e profissional, oportunizando a eles uma inserção social de forma mais igualitária (FONSECA, 2011).

A escola, como oportunidade de ascensão e inclusão social, teve o acesso e a gratuidade garantidos como direitos individuais na Constituição de 1946, pormeio dos Artigos 166 e 168, em seu parágrafo II. Discorrem os artigos sobre a fundamentação que torna o ensino oficial e acessível a todos, entretanto, Anísio Teixeira já assinalava para o paradoxo dessa garantia, afirmando que o direito de acesso à educação não seria garantido se a estrutura organizacional escolar não se adequasse aos novos sujeitos da educação, à época (TEIXEIRA, 1967). Referia-se aos recém-chegados ao espaço escolar, fazendo menção aos filhos das camadas mais pobres.

Para Anísio Teixeira, oportunizar legalmente o ingresso na escola a estes sujeitos não era o suficiente. Necessitava-se o remodelamento do sistema escolar para que o atendimento a todos fosse efetivo e a continuidade, nos anos seguintes, uma realidade. Assim, durante a sua atuação na Secretaria de Educação da Bahia, o educador enxergou a oportunidade de projetar uma escola cidadã e ética e que atendesse às classes pobres sem fazer distinções. Nessa escola seriam propiciadaa diferentes aprendizagens na formação de hábitos, no trabalho e no desenvolvimento intelectual, cuja culminância se dá com a inauguração do Centro Popular de Educação Carneiro Ribeiro, em 1950, em Salvador.

O Centro era composto por dois espaços físicos separados, as Escolas-Classe e Escola-Parque. As Escolas-Classe eram organizadas para a evolução das aprendizagens de cunho intelectual, nela os alunos eram separados por idade/série, seguindo os pressupostos das escolas tradicionais no que tange à organização e carga horária. No período oposto ao da sala de aula, os alunos frequentavam a Escola-Parque que se localizava no centro da cidade. Assim, os alunos oriundos das Escolas-Classe eram transportados, de ônibus, para a continuidade das atividades que abordavam diferentes aspectos da vida humana: trabalho (artes aplicadas, industriais e práticas), educação física (jogos, recreação e ginástica), atividades sociais (grêmio, jornal, rádio escola, banco e loja), expressão artística (música instrumental, canto, teatro e dança), extensão cultural e biblioteca (leitura, estudo, pesquisa) (EBOLI, 1969).

A proposta de Educação Integral, por meio desse Centro, requeria organizar práticas para que os alunos tivessem acesso a conhecimentos que ultrapassassem as aprendizagens formais, inclusive com o reconhecimento e a incorporação de suas experiências fora do espaço escolar, tidas como necessárias à preparação para a vida, para a sociedade e seus constantes desafios. Tratava-se de oportunizar experiências educacionais e sociais que incluíssem efetivamente todos os alunos e seus saberes, na escola e na sociedade.

O Centro Carneiro Ribeiro teve impacto na sociedade baiana, pois permitiu aos alunos de comunidades menos favorecidas uma aproximação e uma reapropriação de espaços 
sociais que lhes eram negados. Dessa forma, a escola representava uma presença efetiva do Estado naquele território, ao ofertar e garantir o acesso e a permanência escolar, tornando possibilidade o crescimento pessoal e profissional aos sujeitos que ali estavam inseridos e que, em geral, encontravam-se abandonados. Tal inserção, segundo Nunes (2010), poderia subsidiar transformações sociais e democráticas. ${ }^{2}$

Em 1950, enquanto Anísio Teixeira implementava sua experiência de Educação Integral no âmbito do ensino público na capital baiana, o país elegia como presidente, pelo voto popular, Getúlio Vargas, cujo governo foi caracterizado por dualidades e radicalizações populistas. De um lado, nacionalistas que objetivavam o monopólio estatal do petróleo e, de outro, os que requeriam a abertura ao capital externo foram constituindo um campo de tensão num governo que tinha o apoio de trabalhadores da máquina sindical e de setores nacionalistas das forças armadas (CARVALHO, 2003). A batalha ganha entre os setores adeptos ao monopólio do petróleo tem repercussão e desdobramentos na política nacional, instaurando a retomada de uma cultura popular nacionalista entre os cidadãos que passaram a entender serem as condições mínimas de vida, responsabilidade do Estado. Contudo, o Governo, à época, estabeleceu uma relação com a população, tendo por base a benesse e não o direito da cidadania, o que acabou por afirmar um modo de relação de poder que se estabelece até hoje. Daí que, enquanto herança, afirma Sales (1994) “[...] o estilo patrimonialista de gestão sócio estatal, marcado pelo predomínio das relações pessoais e não pelo reconhecimento do outro como sujeito de direitos, é também "espelho" da ausência de mediações sociais e institucionais do mundo social”, enfatiza Fedozzi (2001, p. 92, grifo do autor).

Disso resulta que a sociedade brasileira viveu e vive o seu processo de consolidação democrático com dificuldades no que tange à execução da garantia de seus direitos básicos, tornando claro, por meio da contextualização histórica, que não foi somente a educação pública que caminhou a passos lentos. Demandava-se, ao mesmo tempo, a necessidade de reestruturação dos demais sistemas de atendimentos sociais: assistência, saúde, cultura, entre outros. Enquanto resultado da instabilidade das organizações políticas, atrelada à morosidade do reconhecimento de direitos sociais, viveu-se anos de luta por uma educação pública de caráter universal.

Mais tarde, ainda na busca pela reformulação da escola pública, e seguindo os pressupostos defendidos por Anísio Teixeira, entra em cena um antropólogo de suma importância no cenário educacional brasileiro. Darcy Ribeiro, fundador da Universidade de Brasília, no ano de 1961, foi atuante em diferentes causas educacionais e, em 1980, como Secretário de Educação, na gestão do Governo de Leonel Brizola, no Rio de Janeiro, elaborou uma proposta de educação que ultrapassava os espaços da sala de aula e do ensino tradicional. Em seus discursos, reiterava a preocupação com o sistema de ensino público no país, pontuando que a escola disponibilizada e acessível à sociedade de então não tinha a intenção de educar. Dados sobre o fracasso escolar, referentes às escolas da cidade do Rio de Janeiro, demons-

2 Centro Educacional Carneiro Ribeiro, Escola Parque de Salvador, continua com o atendimento de alunos, exercendo atividades com o apoio do Governo do Estado da Bahia. Disponível em: http://www.escolaparquesalvador.com.br/?post type=external-videos\&p=381. Acesso em: 31 mai., 2014. 
travam que a metade dos alunos não passava para a segunda série, justificando as preocupações de Ribeiro com a escola. O educador referia a situação enquanto uma grave doença, de âmbito nacional, impeditiva da transformação social (RIBEIRO, 1984).

Com uma atenção voltada às crianças e aos adolescentes de classes populares, Ribeiro lutou constantemente por investimentos na educação; pautava-se pelo anseio de ofertar oportunidades de crescimento intelectual, ético e pessoal. Em seu relato para a Separata, seção do Jornal Releitura, de 29 de fevereiro de 1996, ao analisar a realidade do Estado do Rio de Janeiro, afirmou que:

\footnotetext{
Só uma escola nova, concebida com o compromisso de atender as condições objetivas em que se apresenta o alunado das classes menos favorecidas, educará o Brasil. Só uma escolarização de dia completo, com professores especialmente preparados e de rotina educativa competentemente planejada, acabará com o menor abandonado, que só existe no Brasil (RIBEIRO, 2003, p. 158).
}

Ainda na década de 1980, o Brasil foi marcado pelo processo transitório entre a ditadura militar e o movimento Diretas Já, organizando-se em torno da sua redemocratização, passava a contar com os setores econômicos e políticos para se autoavaliar vislumbrando, dessa forma, o crescimento nacional. Educadores brasileiros também se inseriram nesse processo de abertura nacional e, por meio da realização de seminários e conferências, constatavam que o ensino público, no país, permanecia excludente e necessitava de reformas práticas, planejamento e legislações (COLLEONI, 2008).

Darcy Ribeiro, consciente da necessidade de mudanças, e a exemplo de Anísio Teixeira, buscava por uma educação de qualidade e atenta para o desenvolvimento ético e democrático dos cidadãos brasileiros. Para tanto, elaborou uma proposta de escola indicando a Educação Integral como a solução para um país com diversos problemas estruturais. Nessa escola, organizada para o acesso a todos e focada para a vida em sociedade, os alunos formariam a consciência dos seus direitos e deveres, preparando-se para atuar nas mudanças políticas e sociais (BOMENY, 2008).

Para tanto, foram criados, em 1981, no Estado do Rio de Janeiro, os Centros Integrados de Educação Pública (CIEPs). Eles tinham como objetivo a ampliação da jornada escolar para, no mínimo, seis horas diárias divididas entre aulas que compunham o currículo escolar e propostas de atividades que envolviam diversos conhecimentos, entre eles, artes, esporte e cultura. Os CIEPs foram implantados nas duas gestões do Governo Leonel Brizola, totalizando, em 1983, 200 escolas. Em 1991, eram 400 escolas, todas arquitetadas por Oscar Niemayer e nelas cada estrutura escolar contava com três blocos conforme descreve Cavaliere (s/d, p. 5):

No bloco principal, ficam as salas de aula, centro médico, cozinha, refeitório e um grande pátio coberto. No segundo bloco, fica o ginásio com vestiário e quadra polivalente (utilizada também para apresentações teatrais, shows, etc.). No terceiro bloco, fica a biblioteca e sobre ela as moradias para alunos residentes. Ainda segundo o projeto original, os CIEPs contariam com professores de educação física, artes, estudos dirigidos, teleducação e animadores culturais. 
Nota-se que a estrutura elaborada por Darcy Ribeiro vai ao encontro da proposta de Anísio Teixeira, porque ambas as experiências transcendiam o currículo escolar e caracterizavam-se pelo reconhecimento de diferentes aprendizagens para a formação do sujeito, enquanto totalidade. Aprimorar a qualidade da educação oferecendo uma formação integral necessária às transformações democráticas, éticas e sociais, era o norte das propostas de Ribeiro no que tange à escola pública brasileira. Estava entranhado em seu projeto de ensino o desejo da construção de uma nova educação, de um sistema de ensino que acompanhasse o desenvolvimento do país, cujos investimentos focassem as crianças e jovens brasileiros em processo de formação. Isto requeria um ensino de qualidade num país que, segundo Ribeiro, existiam crianças abandonadas nas ruas porque não havia escolas que oferecessem qualidade nos serviços e que o Estado, simplesmente, esquecia-se delas.

Nesse sentido, os CIEPs foram criados e geridos com a intenção de atender à crescente demanda de alunos excluídos do espaço escolar, retirando-os das ruas e lhes ofertando educação, cultura, lazer e alimentação. Os CIEPs, portanto, priorizavam um tipo de aluno que precisava de alimentação entre outras condições mínimas para estar na sala de aula. Assim, Ribeiro e sua proposta de Educação Integral articulava todos os âmbitos da constituição dos sujeitos, oferecendo assistência e oportunidades para o desenvolvimento integral dos mesmos.

Não obstante, quando da sua implantação, os CIEPs receberam variadas críticas que decorriam desde o alto investimento financeiro, a arquitetura exuberante até a elaboração da proposta pedagógica. Segundo Aranha (2006), em 1995, Luiz Antônio da Cunha, reconhecido sociólogo e Doutor em Educação, pronunciou-se sobre os CIEPs, mencionando que as instituições não tinham clareza quanto às orientações pedagógico/teóricas e que a preparação docente para a atuação nos Centros tornara-se fatigante. Nessa perspectiva, apontava a Educação Integral enquanto prática meramente assistencialista, afirmando que esse modelo de escola estava tomando para si a incumbência da resolução de temas sociais o que, segundo ele, era inconcebível. ${ }^{3}$

\section{O Ensino Público a partir da Constituição Federal de 1988 e o Progra- Ma Mais EducaÇão}

A Constituição Federal de 1988 propôs reformulações e reorganizações no sistema educacional brasileiro. Entendendo a educação como direito fundamental, por meio da

\footnotetext{
3 Em defesa às ideias de Darcy Ribeiro, Pedro Simon, senador da República do Brasil discorreu: "Sei que muitos acham que aquelas escolas de tempo integral não foram a solução ideal para a educação brasileira porque não tínhamos recursos para implantá-las na sua inteireza. Mas concordo com Darcy quando ele dizia que as crianças não deveriam estar nas ruas, que necessitavam de um lugar agradável onde pudessem passar o dia e tivessem atendimento integral, de educação, cultura, lazer, saúde e alimentação. Darcy queria que os prédios das escolas fossem amplos, limpos e arejados para que as crianças se sentissem bem lá, valorizadas" (RIBEIRO, 2003, p. 10). Entre polêmicas, Darcy Ribeiro, a partir de sua experiência, deixou como legado a necessidade de atentar para um ensino de qualidade, garantido pelo Estado, na busca da formação de sujeitos capazes de atuar em uma sociedade democrática.
} 
qual os sujeitos constroem relações com o mundo e com o Outro, constitui-se da junção de conhecimentos formais e não formais, cujo acesso permite processos de reflexão e diálogo, tornando-a eminentemente um fenômeno social. São os artigos $6^{\circ}$., $205^{\circ}$. e $206^{\circ}$. que apontam para esse direito público, responsabilizando o Estado e as famílias pelo acesso ao ensino em igualdade de condições e a permanência com qualidade.

Por sua vez, no que se refere aos direitos de crianças e adolescentes no Brasil, o Estatuto da Criança e do Adolescente - ECA ressalta a importância do direito e acesso à educação, destacando, no Capítulo IV, artigo $53^{\circ}$. e inciso V, conforme segue:

Art. $53^{\circ}$ : A criança e o adolescente têm o direito à educação, visando ao pleno
desenvolvimento de sua pessoa, preparo para o exercício da cidadania e quali-
ficação para o trabalho, assegurando-lhes:
[...]
V - acesso à escola pública e gratuita próxima a sua residência.
Parágrafo único. É de direito dos pais ou responsáveis terem ciência do proces-
so pedagógico, bem como participar da definição das propostas educacionais
(BRASIL, 1990).

A partir dessas legislações, de esforços governamentais mas, especialmente, consequência do embate travado pelos movimentos sociais, a educação, em termos quantitativos, apresentou crescimento positivo no cenário brasileiro. ${ }^{4} \mathrm{O}$ Ensino Fundamental, obrigatório e da responsabilidade de Estados e municípios, passou a dividir as obrigações/ações/práticas educativas entre todas as esferas governamentais. ${ }^{5}$ Soma-se a isso, em 1996, a promulgação da Lei de Diretrizes e Bases da Educação Nacional - LDB - que estabelece os sistemas de ensino no Brasil, tornando universal o direito de acesso e permanência na escola.

A LDB, também, foi a primeira normativa que fez referência, mesmo que de forma sutil, à ampliação do tempo de permanência na escola, propondo a oferta da modalidade de ensino Educação Integral como uma meta a ser progressivamente atingida.

Art. 34: A jornada incluirá pelo menos 4 horas de trabalho efetivo em sala de aula, sendo progressivamente ampliado o período de permanência na escola.

Parágrafo $2^{\circ}$ : O ensino fundamental será ministrado progressivamente em tempo integral, a critério dos sistemas de ensino.

4 No Brasil, a taxa de analfabetismo da população de 15 anos de idade ou mais, entre 1986 e 1997, passou de $20 \%$ para 14,7\%. Os valores para os anos de 1987, 1988, 1989, 1990, 1991, 1992, 1993 e 1995 foram, respectivamente, $20 \% ; 17 \% ; 19,7 \% ; 19 \% ; 19 \% ; 18,3 \% ; 16,3 \%$ e 15,5\%. Fonte: IBGE, Censo Demográfico 1991 e Pesquisa nacional por amostra de domicílios 1986-1990, 1992-1993, 1995, dados não publicados. Disponível em:<http://www.ibge.gov.br/home/estatistica/populacao/ condicaodevida/indicadoresminimos/ notasindicadores.shtm>. Acesso em: 23 mai., 2014.

5 A Lei 12.796, de 4 de abril de 2013, alterou no seu Artigo 4., a Lei 9.394, de 20 de dezembro de 1996, que estabelecia as diretrizes e bases para a educação nacional, no que tange ao acesso e permanência no espaço escolar. Passou a ser obrigatória a matrícula de crianças e adolescentes entre 4 e 17 anos de idade, nas modalidades de Pré-escola, Ensino Fundamental, Ensino Médio e Educação Infantil de forma gratuita. 
Art. 87. Parágrafo $5^{\circ}$ : Serão conjugados todos os esforços, objetivando a progressão das redes escolares públicas urbanas de ensino fundamental para o regime de escolas de tempo integral (BRASIL, 1996).

Reflexo, segundo Draibe (2003), inclusive, dos esforços governamentais do ex-presidente Fernando Henrique Cardoso (FHC) que, entre os anos de 1994 a 2002, produziram avanços significativos no que tange às propostas de programas sociais públicos visando à melhora no acesso aos serviços oferecidos pelo Estado, entre eles, a educação. Política Pública que passa a ser discutida dentro do eixo de Combate à Fome ${ }^{6}$ objetivando a melhora em aspectos escolares: reforçando o direito à qualidade de ensino e à merenda escolar. Por sua vez, a reforma do Ensino Fundamental propôs o aprimoramento da qualidade e dos conteúdos curriculares, avaliação do sistema educacional e financiamento por meio do Fundo de Desenvolvimento do Ensino Fundamental e de Valorização do Magistério (Fundef) o que também, segundo a autora, teve impacto positivo nas metas de acesso e permanência na escola.

Assim, as propostas e as ações elaboradas durante esse governo foram de extrema importância para a construção de novas proposições ao sistema educacional, principalmente no que diz respeito à relação entre União, Estados e Municípios. Por sua vez, os mandatos do ex-presidente Luiz Inácio Lula da Silva (Lula), entre os anos de 2003 a 2010, foram marcados pela continuidade, renovação e ampliação das políticas sociais. Em sua primeira gestão, foi dado prosseguimento aos programas iniciados no governo de FHC, entre eles, o Bolsa Escola. No segundo mandato, Lula focou a gestão pública nas causas sociais, implantando programas que visavam ao aumento de oportunidades de formação, renda, acesso à educação e combate à fome.

O maior deles, o Programa Bolsa Família ganhou popularidade, investimentos e tem estreitados os laços com os demais direitos sociais básicos. Por exemplo, as famílias beneficiadas pelo Programa devem cumprir algumas condições para ter acesso ao benefício, como: participar ativamente do desenvolvimento de crianças até 7 anos de idade, no que tange às questões de saúde e vacinação; matricular todas as crianças e adolescentes entre 6 e 17 anos no ensino público, bem como, acompanhar a frequência mensal dos mesmos; manter crianças e adolescentes em risco ou retiradas do trabalho infantil vinculadas aos Serviços de Convivência e Fortalecimento de Vínculos do Ministério de Desenvolvimento Social (MDS).

Apesar desses investimentos, os índices educacionais continuavam a apontar a repetência, defasagem idade/série e evasão escolar, principalmente, entre aqueles que necessitavam trabalhar durante o período das aulas, desenvolvendo atividades que contribuíam para o sustento familiar. Outro motivo que evidencia a evasão escolar se refere à falta de interesse que

6 O Plano de Combate à Fome objetivou a melhora na qualidade de vida dos sujeitos menos favorecidos financeiramente. Buscou-se a geração de empregos e renda, qualificação profissional, saneamento, redução da mortalidade infantil, alimentação e maior desenvolvimento e investimento na educação básica no país. Essas ações foram executadas por meio de diferentes programas organizados e executados pelos ministérios da Previdência e Assistência Social, Saúde e Trabalho, Justiça, Planejamento e Orçamento, Educação, Esporte e Fazenda. 
os alunos demonstram em permanecer na escola. A apropriação de conteúdos curriculares demasiado longe do contexto social e familiar é uma das hipóteses para o afastamento.

Conforme Kruppa (1994, p. 99):

O currículo escolar muitas vezes está formulado de maneira distante da realidade do aluno. Nesse caso, a forma de organização do conhecimento escolar torna-se uma barreira ao estabelecimento de relações, por parte dos alunos, sobre esse conhecimento, que se torna memorizado por exaustivas repetições sem significado.

Conteúdos que não fazem referência à vida, quando somados a práticas didáticas pouco atrativas permitem aos alunos, por vezes, não se identificar com o ambiente escolar. Para estes, a escola torna-se um fardo pesado a ser carregado e, quando o cansaço e o desinteresse prevalecem, o abandono é a solução. Os motivos que levam o aluno à renúncia ao espaço escolar apresentam-se de diferentes formas, porém, remetem para a mesma indagação: estará a escola perdendo espaço na vida de crianças e adolescentes? Questões já presentes nas preocupações de Ribeiro (1984, p. 57) quando reflete: "se fala de alunos evadidos, como se tratasse de malandros desertores, que fugiram da escola. Uma visão mais objetiva olharia a evasão como resultante da rejeição do aluno pela escola".

Dessa forma, percebe-se que a instituição escolar tem como desafio, desde longa data, proporcionar às crianças e adolescentes uma formação escolar que seja, ao mesmo tempo, produtora de cidadania, lugar de desejo e de, no nosso entendimento, proteção social. Nesse sentido, a educação assume valor de direito humano fundamental.

Tal afirmação, no que tange à proteção, demanda por uma contextualização. Atualmente, a proteção social no campo da educação emerge e se consolida, principalmente, por meio de projetos socioeducativos ${ }^{7}$ que, na grande maioria das vezes, são realizados por entidades governamentais, não governamentais e de terceiro setor do campo da assistência social. Recentemente, o Programa Mais Educação é apresentado pelo próprio Ministério da Educação e Cultura (MEC) como o grande articulador de estratégias educativas que, por meio de oficinas, implementa estratégias de proteção aos menos favorecidos. Tem na ampliação do tempo de permanência na escola de Ensino Fundamental, ao menos em tese, o fortalecimento das aprendizagens e a formação ampla aos que estão matriculados na modalidade de educação integral.

Essas propostas estão atreladas aos seguintes programas: Programa Segundo Tempo, Programa Esporte Lazer na Cidade, Programa Cultura Viva, Programa Cineclube na Escola, Programa Casas do Patrimônio, ProJovem Adolescente - Serviço Socioeducativo, Centro de Referência Especializado de Assistência Social - CREAS, Centro de Referência de Assistência Social - CRAS e Programa de Atenção Integral à Família - PAIF, Programa de Erradicação do Trabalho Infantil (PETI), Programa Centros Vocacionais Tecnológicos (CVTs), Programa Casa Brasil Inclusão Digital, Programa Centros e Museus de Ciência no Brasil, Programa Com -Vidas - Comissão de Meio Ambiente e Qualidade de Vida, Programa Educação em Direitos Humanos, Programa de Educação Inclusiva: Direito à Diversidade, Projeto Educar na Diversidade, Programa Escola Aberta, Programa Escola que Protege, Programa Salas de Recursos Multifuncionais, Programa ProInfo, Programa Municípios Educadores Sustentáveis, Programa Sala Verde, Programa Viveiro Educadores (BRASIL, 2009a). 
O referido Programa proporciona a ampliação de tempo, espaços e oportunidades educacionais baseando-se no pressuposto da formação integral. Esta se expressa pela conexão das aprendizagens da sala de aula, as vivências em oficinas de áreas diversas, os saberes comunitários que adentram a escola por meio de diferentes parcerias, a oferta de alimentação entre os turnos. Realidades que acrescem para sete horas diária a carga horária mínima de permanência na escola e em consonância com as legislações, entre elas, os Planos Nacionais de Educação (2001-2011 e 2014-2024) vem marcando o lugar da ampliação da jornada escolar na educação pública brasileira.

O PME é financiado pelo Programa Dinheiro Direto na Escola (PDDE/Educação Integral) que destina recursos para o funcionamento das atividades nas instituições participantes. Esses valores são disponibilizados para a aquisição de materiais de consumo necessários para a realização das oficinas, pagamento de despesas com alimentação e transportes dos monitores voluntários (BRASIL, 2014a).

Segundo o Manual Operacional da Educação Integral (BRASIL, 2014, p. 21), as escolas que desejam aderir ao Programa devem enquadrar-se em um destes requisitos:

- Escolas contempladas com PDDE/Integral nos anos de 2008, 2009, 2010, 2011 e 2012;

- Escolas estaduais, municipais e/ou distritais que foram contempladas com o PDE/Escola e que possuam o IDEB abaixo ou igual a 3,5 nos anos iniciais e/ ou finais, IDEB anos iniciais $<4.6$ e IDEB anos finais $<3.9$, totalizando 23.833 novas escolas;

- Escolas localizadas em todos os municípios do país;

- Escolas com índices igual ou superior a 50\% de estudantes participantes do Programa Bolsa Família.

A seleção dos alunos para a inserção no PME, por sua vez, ocorre a partir de critérios específicos: defasagem idade/escolaridade, histórias de repetências e evasão da escola e, os estudantes cujas famílias são beneficiárias do Programa Bolsa Família têm preferência nas matrículas em Educação Integral. No conjunto, tais critérios permitem apontar a dimensão de política afirmativa presente no Programa.

\section{À GUISA DE CONSIDERAÇÕES FINAIS}

Com o propósito de demarcar a relevância da ampliação da jornada escolar como definido por Moll (2012), ao destacar a produção de uma imensa ressignificação do que seja a educação escolar, não é possível deslocar a emergência do PME das contribuições de Anísio Teixeira e Darcy Ribeiro, por meio do Centro Carneiro Ribeiro e dos Centros Integrados de Educação Pública, respectivamente. Em ambas as experiências, há necessidade de qualificar a educação pública necessária à consolidação da democracia no país. Teixeira e Ribeiro perseguiram a oferta de um ensino que atentasse para o pleno desenvolvimento dos sujeitos da educação, a fim de que portassem subsídios para atuar em sociedade e, para que, principalmente, incorporassem experiências de práticas emancipatórias necessárias às 
transformações em face das diferentes demandas sociais e econômicas do país dos anos de 1950 e 1980.

Recentemente, nos anos 2000, o Programa Mais Educação reaviva as propostas desses educadores no que tange à aproximação dos educandos com atividades de formação humana mais amplas. Nesse sentido, o PME reafirma ser necessária a ampliação da jornada escolar oferecendo uma formação para além da sala de aula, por meio de práticas socioeducativas que ultrapassem as aprendizagens centradas no currículo escolar. O Programa, também, a seu tempo, reconhece a existência de setores da sociedade que, se não se encontram fora da sala de aula, inclusive, por força de políticas sociais e legislações de proteção, vivem a precariedade de experiências educativas excludentes. Isto fica ainda mais evidente quando colocamos em relevo as desvantagens de crianças e adolescentes das classes populares em comparação àquelas matriculadas em tempo integral, nas escolas particulares.

Formar o sujeito na sua totalidade, considerando questões sociais, práticas culturais e de lazer, aproximando a realidade do aluno ao espaço escolar supõe, não sem contradições, que crianças e adolescentes somem à sua capacidade de aproveitamento escolar, a compreensão e o reconhecimento de outros saberes educativos que circulam nas instâncias familiares, comunitárias, entre outros. Assim, o ensino público torna-se mais efetivo na formação social por meio de experiências socioeducativas diversificadas, conforme os pressupostos de Anísio Teixeira e Darcy Ribeiro.

Por fim, é importante destacar que as experiências propostas por esses educadores objetivavam uma educação integral, universal, que atingisse todas as crianças e adolescentes matriculadas na escola pública, ainda que por meio de experiências locais. Para ambos, a qualificação da escola era a garantia de permanência daqueles com históricos de evasão, questão retomada pelo PME na atualidade. Contudo, enquanto Teixeira postulava que os alunos das classes populares experienciassem vivências democráticas garantidas na escola de educação integral, Ribeiro, ao compartilhar da ideia, propunha, também, uma formação crítica e, ao mesmo tempo, sensível aos dilemas de uma sociedade que vivia a abertura democrática, após anos de uma brutal ditadura. Daí ser possível afirmar que, no conjunto, a Educação Integral no Brasil em suas duas experiências mais expressivas, mesmo que pontuais, construíram seus fundamentos colados na necessidade de mudanças sociais mais amplas. Nelas, a garantia de direitos, como, o acesso e a gratuidade de oferta de ensino estão associados muito especialmente à consolidação da sociedade democrática.

Por sua vez, o PME, ao se constituir numa experiência de abrangência nacional, embora não universal, não se ocupa diretamente em formar um cidadão crítico. Tampouco está centrado nas necessidades de transformação política da sociedade, também, porque foi criado na conjuntura de um governo democrático e popular. Nem por isso o Programa deixa de ter forte caráter político. Nesse sentido, pelo evidente valor de política afirmativa e de caráter compensatório, o Programa aproxima-se do proposto por Castel (2008) que, ao defender a discriminação positiva, permite recuperar o sentido da educação enquanto direito humano. Contrariamente à escandalosa discriminação negativa, a versão positiva consiste, segundo Castel (2008, p. 13), em "fazer mais aos que tem menos". Assim, ao 
compreendermos as políticas afirmativas focadas em determinados segmentos sociais, no bojo do enfrentamento às desigualdades que afligem a sociedade brasileira, de imediato, localizamos a dimensão política do Programa. E, feitas essas considerações, julgamos que o PME também se constitui enquanto experiência histórica ao defender a ampliação da jornada escolar ao modo de seus antecessores.

\section{REFERÊNCIAS}

ALMEIDA, Carlos. A Cabeça do Brasileiro. Rio de Janeiro: Editora Record, 2007, 280p. ARANHA, Maria Lucia A. História as Educação e da Pedagogia: Geral e Brasil, 3. ed. São Paulo: Moderna, 2006, 384p.

BOMENY, Helena. A escola no Brasil de Darcy Ribeiro. Em Aberto. v. 22, n. 80, p. 109120, abr., 2008. Disponível em:

http://www.emaberto.inep.gov.br/index.php/emaberto/article/viewFile/1474/1223 Acesso em: 26 jun., 2015.

BRASIL. Constituição da República Federativa do Brasil. Brasília: Casa Civil, 1988. Disponível em: http://www.planalto.gov.br/ccivil_03/constituicao/constituicao.htm Acesso em: 24 nov., 2015.

. Lei $n^{\circ} .8 .069$, de 13 de julho de 1990. Dispõe sobre o Estatuto da Criança e do Adolescente e dá outras providências. Diário Oficial da União, Brasília, DF, 13 de julho de 1990. Disponível em: http://www.planalto.gov.br/ccivil_03/leis/L8069Compilado.htm Acesso em: 26 jul., 2015.

. Lei no. 9.394, de 20 de dezembro de 1996. Estabelece as Diretrizes e Bases da Educação Nacional. Diário Oficial da União, Brasília, DF, 20 de dezembro de 1996. Disponível em: http://www.planalto.gov.br/ccivil_03/leis/L9394.htm. Acesso em: 27 jul., 2015.

. Programa Mais Educação: gestão intersetorial no território, Brasília: Ministério da Educação, Secretaria de Educação Continuada, Alfabetização e Diversidade, 2009a., $102 p$.

. Rede de Saberes Mais Educação: pressupostos para projetos pedagógicos da educação integral: caderno para professores e diretores de escolas. Brasília: Ministério da Educação, Secretaria de Educação Continuada, Alfabetização e Diversidade, 2009b., 92p.

. Programa Mais Educação: Passo a Passo. Brasília: Ministério da Educação, Secretaria de Educação Básica, 2011, 36p.

. Manual Operacional de Educação Integral. Brasília: Ministério da Educação, 2014, 71p. Disponível em: http://portal.mec.gov.br/index.php?option=com 
docman\&view=download\&alias=11452-manual-operacional-de-educacao-integral-2012-pdf\&category_slug=agosto-2012-pdf\&Itemid=30192 Acesso em: 15 out., 2015.

. FUNDEB. Ministério da Educação, 2014a. Disponível em: http://portal.mec.gov. br/index.php?option=com_content\&id=12407/. Acesso em: 29 out., 2014.

CARVALHO, José Murilo. Cidadania no Brasil, o longo caminho. Rio de Janeiro: Civilização brasileira, 2003, 236p.

CASTEL, Robert. A discriminação negativa - Cidadãos ou autóctones? Petrópolis: RJ, 2008.

CAVALIÉRE, Ana M. V. Memória das Escolas de Tempo Integral do Rio de Janeiro (CIEPs): documentos e protagonistas. Rio de Janeiro: UFRJ [entre 1994 e 2006]. Disponível em: http://www.sbhe.org.br/novo/congressos/cbhe1/anais/017_ana_maria_vilella.pdf. Acesso em: 10 jun., 2014.

COLLEONI, Cristini. Brasil - Anos de 1980, o desejo da democratização e a democracia existente no século XXI. Primeiro Simpósio Nacional de Educação. Cascavel, Paraná, 2008. Disponível em:

http://www.unioeste.br/cursos/cascavel/pedagogia/eventos/2008/5/Artigo\%2037.pdf. Acesso em: 24 jun., 2014.

EBOLI, Terezinha. Uma experiência de educação integral: Centro Educacional Carneiro Ribeiro. Salvador: MEC/INEP, 1969, 84p.

FEDOZZI, Luciano. Orçamento Participativo. Reflexões sobre a experiência de Porto Alegre. Porto Alegre: Tomo Editorial, RJ: UFRJ/IPPUR, 3. ed., 2001.

FONSECA, Sérgio C. Paulo Freire \& Anísio Teixeira: Convergências e Divergências. Jundiaí, Paco Editorial, 2011, 270p.

GADELHA, Sylvio. Biopolítica, governamentalidade e educação: Introdução e conexões, a partir de Michel Foucault. Belo Horizonte: Autêntica Editora, 2009, 238p.

KRUPPA, Sonia Maria P. Sociologia da Educação. São Paulo: Cortez, 1994, 157p.

MAURICIO, Lucia V. Representações do jornal O Globo sobre os Cieps [s/l], [entre 1994 e 2006]. Disponível em: http://www.anped.org.br/reunioes/30ra/trabalhos/GT132730--Int.pdf. Acesso em: 24 out., 2013.

MOLL, Jaqueline (Org.). Caminhos da educação integral no Brasil: direito a outros tempos e espaços educativos. Porto Alegre: Penso, 2012, 504p.

NUNES, Clarice. Anísio Teixeira. Recife: Fundação Joaquim Nabuco, Editora Massangana, 2010, 152p.

RAPOSO, Gustavo R. A educação na Constituição de 1988, 2005. Disponível em: http://jus. com.br/artigos/6574/a-educacao-na-constituicao-federal-de-1988. Acesso em: 24 jun., 2014. 
RIBEIRO, Darcy. Nossa escola é uma calamidade. Rio de Janeiro: Salamandra, 1984, $106 \mathrm{p}$.

. Grandes vultos que honraram o Senado: Darcy Ribeiro. Editado por Pedro Simon, Brasília: Senado Federal, Subsecretaria de Edições Técnicas, 2003, 212p.

SALES, Teresa. Raízes da desigualdade social na cultura política brasileira. Revista Brasileira de Ciências Sociais, São Paulo, n. 25, p. 26-37, 1994. Disponível em: http:// www.anpocs.org.br/portal/publicacoes/rbcs_00_25/rbcs25_02.htm. Acesso em: 24 mai., 2014.

TEIXEIRA, Anísio. Educação é um direito: dependência essencial da democracia da efetivação desse direito; a educação como problema político e sua organização e administração como serviço público especial autônomo; bases para um plano de organização dos sistemas estaduais de educação. São Paulo: Nacional, 1967, 166p.

Dados das Autoras

Camila Altmayer Valentini

Mestra em Diversidade Cultural e Inclusão pela Universidade Feevale. Professora de Educação Infantil - Colégio Santa Catarina. Novo Hamburgo/RS - Brasil. k.altmayer@gmail.com

\section{Dinora Tereza ZucchetTi}

Doutora em Educação pela Universidade Federal do Rio Grande do Sul. Professora da Universidade Feevale. Novo Hamburgo/RS - Brasil. dinora@feevale.br

Submetido em: 07-01-2016

Aceito em: 14-02-2017 